\title{
Response of autoimmune and inflammatory disorders in myelodysplastic syndromes to 5-azacytidine: report of two cases and literature review
}

\author{
Dan-Yang Wu", Jing Wang", Rui Zhang, Xiao-Jing Yan, Ran Gao \\ Department of Hematology, the First Affiliated Hospital of China Medical University, Shenyang, China \\ \#These authors contributed equally to this work. \\ Correspondence to: Ran Gao. Department of Hematology, the First Affiliated Hospital of China Medical University, No. 155, Nanjing North Street, \\ Shenyang, China. Email: emma1213emma@126.com.
}

\begin{abstract}
Paraneoplastic autoimmune and inflammatory disorders are often associated with myelodysplastic syndromes (MDS). The etiopathogenesis of MDS-associated autoimmune and inflammatory disorders is still unclear and treatment options are limited. Patients with MDS are at high risk of infections, which can be increased by the use of steroids. In the present study, we report on two patients with MDSrelated autoimmune and inflammatory disorders who were in remission and reduced the steroid dose with 5 -azacytidine treatment. The first case was a 67-year-old patient diagnosed with MDS and the whole-body erythroderma was the chief complaint. When the patient was treated with decitabine, steroid treatment was needed to control the erythroderma. When we changed decitabine to 5 -azacytidine, both his erythroderma and his dependency on the steroid treatment were resolved. The second patient was a 68 -year-old man with MDS who presented with Sweet's syndrome. Sweet's syndrome was completely treated after the first cycle of 5 -azacytidine. In addition, Sweet's syndrome can occur as an adverse reaction of 5-azacitidine, so we illustrate that it is important to distinguish whether Sweet's syndrome is MDS-related skin disorders or 5-azacitidinerelated skin side-effects.
\end{abstract}

Keywords: Autoimmune and inflammatory disorders; 5-azacytidine; myelodysplastic syndromes (MDS); case report

Submitted May 13, 2021. Accepted for publication Jul 13, 2021.

doi: 10.21037/apm-21-1416

View this article at: https://dx.doi.org/10.21037/apm-21-1416

\section{Introduction}

It has been reported that up to $10-20 \%$ of patients with myelodysplastic syndromes (MDS) manifest autoimmune and inflammatory disorders, including vasculitis, polychondritis, Sjogren syndrome, Sweet's syndrome, and rheumatic arthritis (1). The etiopathogenesis of MDSrelated autoimmune and inflammatory disorders is still undetermined, and the prognostic significance remains debatable. Immunosuppressive therapy is reported to be effective to control the autoimmune and inflammatory manifestations (2). However, many patients are steroid dependent or resistant to immunosuppressive agents, which may increase the risk of infection.
In the present study, we report on 2 patients with dermatological lesions as the first autoimmune and inflammatory manifestations before the diagnosis of MDS. These patients achieved complete remission of dermatological lesions following treatment with 5 -azacytidine. One of the dermatological lesions was erythroderma, which is especially rare as a first manifestation of MDS. To the best of our knowledge, this is first report in which a patient with erythroderma and MDS achieved complete remission of both dermatological lesions and hemogram by switching from decitabine to 5 -azacytidine. The other dermatological lesion was Sweet's syndrome, which has been reported to affect $10 \%$ of cases 
with acute myeloid leukemia (AML) and MDS (3). We present the following article in accordance with the CARE reporting checklist (available at https://dx.doi.org/10.21037/ apm-21-1416).

\section{Case presentation}

\section{Case 1}

A 67-year-old man was admitted to our hospital with wholebody scaling erythema. He was diagnosed with general eczema and recieved cetirizine hydrochloride intermittently for about half a year. However, his erythema gradually worsened and he was obsessed with a fever and swelling of his limbs. He was diagnosed with erythroderma by skin biopsy at the Department of Dermatology of the First Affiliated Hospital of China Medical University. The patient was administrated with $40 \mathrm{mg} /$ day methylprednisolone via vein for 12 days and $28 \mathrm{mg} /$ day by oral continuously. His skin lesions improved gradually and the dose of methylprednisolone was tapered.

Laboratory tests revealed anemia with hemoglobin $99 \mathrm{~g} / \mathrm{L}$ and thrombocytopenia with a platelet count of $62 \times 10^{9} / \mathrm{L}$. The morphology and immunophenotype studies on bone marrow supported the diagnosis of unclassifiable MDS (MDS-U) according to the 2016 World Health Organization classification of MDS with normal karyotype. The polymerase chain reaction screening assay for 41 recurrent fusion genes in acute leukemia were negative. Next-generation sequencing revealed gene mutations in additional sex combs-like 1 (ASXL1), DNA methyl transferase 3 alpha (DNMT3A), and ten eleven translocation 2 (TET2).

According to the low International Prognostic Scoring System (IPSS) risk score, supportive care including erythropoietin and thalidomide was given to the patient. However, the platelet counts of the patient progressively dropped to $10 \times 10^{9} / \mathrm{L}$ and he need platelet transfusions twice a week in the emergency ward. As such, he was hospitalized at our department for further treatment. At that time, he was administered $18 \mathrm{mg}$ /day methylprednisolone with erythroderma still covering his limbs (Figure 1A). He complained that when the dose of methylprednisolone was reduced, the erythroderma aggravated. To handle the patient's problem, treatment with decitabine was started, and 2 cycles later, the platelet count returned to $240 \times 10^{9} / \mathrm{L}$. During the treatment, there were several events of infection on account of methylprednisolone and agranulocytosis. So we tried to reduce the dose of methylprednisolone, however, when the dose of methylprednisolone was decreased to $8 \mathrm{mg} /$ day the patient's rash worsened (Figure $1 B$ ). His treatment was changed from decitabine to 5 -azacytidine once per month. After 2 cycles of 5 -azacytidine, the patient's erythroderma resolved and the treatment with methylprednisolone was quitted (Figure 1C). The patient received complete remission and another five cycles of 5 -azacytidine were administrated. However, his platelet counts declined to $63 \times 10^{9} / \mathrm{L}$ just before the sixth cycle. The re-examination of bone marrow indicated that his MDS- $\mathrm{U}$ progressed to MDS with excess blasts 1 . Fortunately, his erythroderma did not relapse. He received two more cycles of 5-azacytidine, but his platelet levels continued to decline. Then he discontinued the treatment for about 3 months due to the influence of the coronavirus disease 2019 . He had erythroderma relapse when the patient returned to our hospital. Upon further examination, acute leukemia was diagnosed. The patient refused ongoing treatment with 5 -azacytidine, so we prescribed venetoclax and $4 \mathrm{mg} /$ day methylprednisolone was required to control the erythroderma. After 1year, the patient died of the infection.

\section{Case 2}

The second patient was a 68 -year-old man who presented with painful erythematous papules all over the body (Figure $2 A$ ) and a fever of $39^{\circ} \mathrm{C}$. Laboratory tests revealed pancytopenia (white blood cell count $1.37 \times 10^{9} / \mathrm{L}$, hemoglobin $59 \mathrm{~g} / \mathrm{L}$, platelets $\left.30 \times 10^{9} / \mathrm{L}\right)$. The patient was diagnosed with Sweet's syndrome based on the skin biopsy results. Subsequently, bone marrow aspiration was performed, and the patient was diagnosed with MDS with multilineage dysplasia with complex karyotype [46-51, XY, $-4,+5 \mathrm{q}-,-6,+8,9 \mathrm{q}-,-10,+11,+12,+13,+15,16 \mathrm{qh}+,+18$, $\left.+\operatorname{mar} 1,+\operatorname{mar} 2,+\operatorname{mar} 3\left(\mathrm{CP} 10 \_/ 46, \mathrm{XY}\right)\right]$ and TP53 gene mutation. He received 3 cycles of 5 -azacytidine, and Sweet's syndrome was successfully treated after the first cycle with no relapse (Figure $2 B$ ). However, his hemogram did not improve and the disease progressed to acute leukemia.

\section{Ethical statement}

The patients provided written informed consent for the publication of the case details and images. All procedures performed in studies involving human participants were in accordance with the ethical standards of the institutional and national research committee and with the Helsinki Declaration (as revised in 2013). 

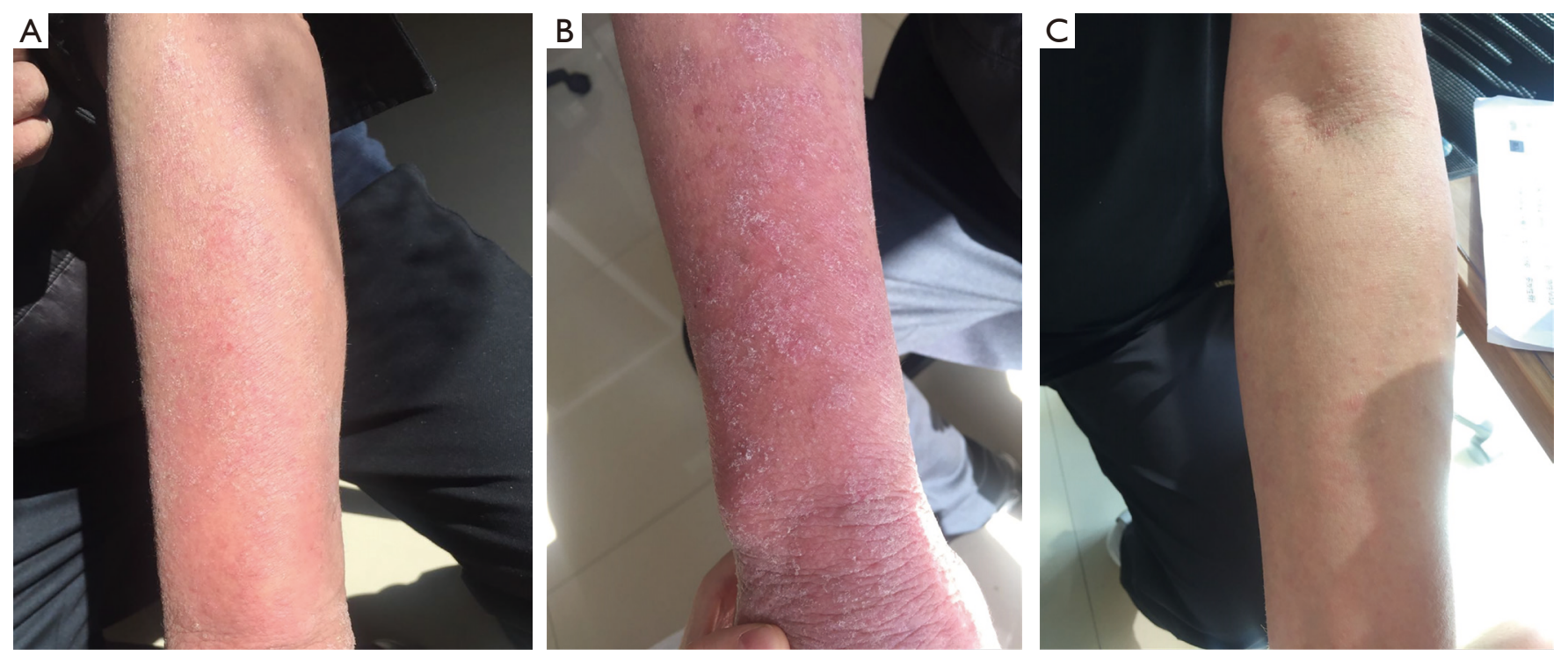

Figure 1 Changes in cutaneous symptoms during treatment of the first patient. (A) Condition of the patient when he was admitted to our department and was treated with $18 \mathrm{mg} /$ day methylprednisolone orally; (B) when methylprednisolone was reduced to $8 \mathrm{mg} / \mathrm{day}$ orally, the patient's rash worsened; (C) after 2 cycles of 5-azacytidine, the patient's cutaneous symptoms were relieved.
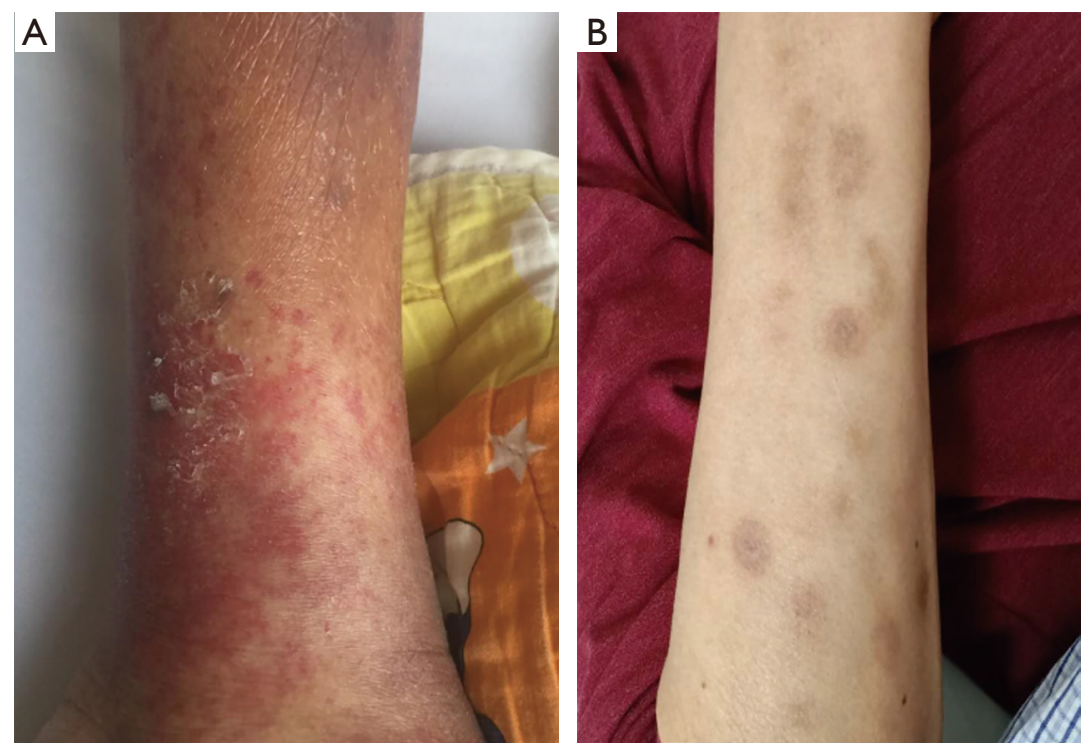

Figure 2 Changes in cutaneous symptoms during the treatment of the second patient. (A) Condition of the patient when he was admitted to our department; (B) after 1 cycle of 5-azacytidine, the patient's cutaneous symptoms were relieved.

\section{Discussion}

Dermatological lesions as manifestations of MDS-related autoimmune and inflammatory disorders are very common, which can be divided into the following two types: hyperkeratotic dermatosis and inflammatory dermatosis (4). Sweet's syndrome and erythroderma are inflammatory dermatosis type. Erythroderma is a rare inflammatory disorder of the skin characterized by erythema, with scaling on $90 \%$ or more of the body surface. Cutaneous 
T-cell lymphoma is the most common malignancy as the etiology of erythroderma (5). AML and MDS are rarely reported in the literature. In contrast, Sweet's syndrome, which is known as acute febrile neutrophilic dermatosis, is characterized by painful erythematous papules or nodules accompanied with fever and is often associated with AML and MDS (6). Identification of paraneoplastic dermatosis is important for the early diagnosis of underlying tumors.

The exact etiopathogenesis of MDS-related autoimmune and inflammatory disorders is unclear. It has been reported that changes to immune cells, including regulatory T-cells, natural killer cells, CD4+ T cells, CD8+ T cells, and various cytokines levels, play an important role $(7,8)$. These changes are not only related to the autoimmune and inflammatory disorders in MDS but also account for the ineffective hematopoiesis and refractory hemocytopenia of MDS. This is why both autoimmune manifestations and the hematological status of MDS can improve simultaneously with the treatment of immunosuppressive agents or demethylation drugs. In most cases, the response of autoimmune disorders and hemogram to treatment did not parallel. In our cases, the erythroderma and hemogram of the first patient improved following treatment with 5 -azacytidine, but only the dermatological lesions of the second patient were relieved.

Corticosteroids and immunosuppressive drugs are used for the conventional treatment of autoimmune and inflammatory disorders in MDS. However, many patients are dependent on steroids or resistant to immunosuppressive drugs, which may increase the risk of infection in patients with cytopenia (9). As a conventional treatment for MDS, 5-azacitidine has immunoregulatory effects, such as reducing the synthesis of inflammatory cytokines and increasing CD4+CD25+/forkhead-box-p3+ regulatory $\mathrm{T}$ cells $(10,11)$. In one study, 5 -azacitidine was found to improve the clinical manifestation of autoimmune disorders in $86 \%$ of MDS/chronic myelomonocytic leukemia patients, reduce the steroid dose of $64 \%$ patients, and suspend the use of other immunosuppressive drugs in $32 \%$ patients (12). Interestingly, Sweet's syndrome can occur as an adverse reaction of 5-azacitidine (13). Because MDS-related autoimmune and inflammatory disorders may come up ahead of the diagnosis of MDS, simultaneously, or even during the illness, it is important to distinguish whether Sweet's syndrome is related to 5-azacitidine. In their case study, Liu et al. found that Sweet's syndrome was related to 5-azacitidine, because the eruptions of Sweet's syndrome followed each cycle of 5 -azacitidine for a total of
12 cycles, with no response to high-dose steroids. Sweet's syndrome was treated successfully once 5 -azacitidine was changed to decitabine (14). When Sweet's syndrome occurs during the treatment of 5 -azacitidine, Lin et al. advised continuing 5 -azacitidine treatment and adding a low-dose steroid to control Sweet's syndrome. After a few cycles, both MDS and Sweet's syndrome may be well controlled (15). In contrast to 5-azacytidine, decitabine has been rarely reported to improve MDS-related autoimmune disorders. 5 -azacytidine is more effective than decitabine in reducing the steroid dose and improving skin lesions, as demonstrated in our first case; however, the specific reason for this is still unclear.

\section{Conclusions}

5 -azacitidine is effective for improving the autoimmune and inflammatory disorders in MDS and can reduce steroid dose. It is also important distinguish MDSrelated skin disorders from 5 -azacitidine-related skin sideeffects. Further investigations should be done to confirm whether 5-azacitidine is effective for treating MDS-related autoimmune and inflammatory disorders.

\section{Acknowledgments}

Funding: This work was supported by Liaoning Revitalization Talents Program under grant XLYC1807265.

\section{Footnote}

Reporting Checklist: The authors have completed the CARE reporting checklist. Available at https://dx.doi. org/10.21037/apm-21-1416

Conflicts of Interest: All authors have completed the ICMJE uniform disclosure form (available at https://dx.doi. org/10.21037/apm-21-1416). The authors have no conflicts of interest to declare.

Ethical Statement: The authors are accountable for all aspects of the work in ensuring that questions related to the accuracy or integrity of any part of the work are appropriately investigated and resolved. The patients provided written informed consent for the publication of the case details and images. The First Affiliated Hospital of China Medical University approved publication of the case details. All procedures performed in studies 
involving human participants were in accordance with the ethical standards of the institutional and national research committee and with the Helsinki Declaration (as revised in 2013).

Open Access Statement: This is an Open Access article distributed in accordance with the Creative Commons Attribution-NonCommercial-NoDerivs 4.0 International License (CC BY-NC-ND 4.0), which permits the noncommercial replication and distribution of the article with the strict proviso that no changes or edits are made and the original work is properly cited (including links to both the formal publication through the relevant DOI and the license). See: https://creativecommons.org/licenses/by-nc-nd/4.0/.

\section{References}

1. Grignano E, Jachiet V, Fenaux P, et al. Autoimmune manifestations associated with myelodysplastic syndromes. Ann Hematol 2018;97:2015-23.

2. Saif MW, Hopkins JL, Gore SD. Autoimmune phenomena in patients with myelodysplastic syndromes and chronic myelomonocytic leukemia. Leuk Lymphoma 2002;43:2083-92.

3. Lee SJ, Park JK, Lee EY, et al. Certain Autoimmune Manifestations Are Associated With Distinctive Karyotypes and Outcomes in Patients With Myelodysplastic Syndrome: A Retrospective Cohort Study. Medicine (Baltimore) 2016;95:e3091.

4. Lim PN, Fox CP, Pammi M, et al. Paraneoplastic erythroderma: unusual presentation secondary to diffuse large B cell lymphoma. BMJ Case Rep 2019;12:e228412.

5. César A, Cruz M, Mota A, et al. Erythroderma. A clinical and etiological study of 103 patients. J Dermatol Case Rep 2016;10:1-9.

6. Cohen PR, Talpaz M, Kurzrock R. Malignancy-associated Sweet's syndrome: review of the world literature. J Clin

Cite this article as: Wu DY, Wang J, Zhang R, Yan XJ, Gao R. Response of autoimmune and inflammatory disorders in myelodysplastic syndromes to 5 -azacytidine: report of two cases and literature review. Ann Palliat Med 2021;10(8):9276-9280. doi: 10.21037/apm-21-1416
Oncol 1988;6:1887-97.

7. Costantini B, Kordasti SY, Kulasekararaj AG, et al. The effects of 5-azacytidine on the function and number of regulatory $\mathrm{T}$ cells and $\mathrm{T}$-effectors in myelodysplastic syndrome. Haematologica 2013;98:1196-205.

8. Matsuzawa Y, Adachi E, Takahashi A, et al. Cytokine Profile in Sweet's Syndrome under the Treatment of Pulmonary Toxoplasmosis Complicated with Myelodysplastic Syndrome. Intern Med 2019;58:2079-2083.

9. Mekinian A, Braun T, Decaux O, et al. Inflammatory arthritis in patients with myelodysplastic syndromes: a multicenter retrospective study and literature review of 68 cases. Medicine (Baltimore) 2014;93:1-10.

10. Poplutz MK, Wessels I, Rink L, et al. Regulation of the Interleukin-6 gene expression during monocytic differentiation of HL-60 cells by chromatin remodeling and methylation. Immunobiology 2014;219:619-26.

11. Goodyear OC, Dennis M, Jilani NY, et al. Azacitidine augments expansion of regulatory $\mathrm{T}$ cells after allogeneic stem cell transplantation in patients with acute myeloid leukemia (AML). Blood 2012;119:3361-9.

12. Fraison JB, Mekinian A, Grignano E, et al. Efficacy of Azacitidine in autoimmune and inflammatory disorders associated with myelodysplastic syndromes and chronic myelomonocytic leukemia. Leuk Res 2016;43:13-7.

13. Berry WA, Kelly R. A case of polycyclic Sweet's syndrome arising from azacitidine injection sites in myelodysplasia. Ann Hematol 2020;99:201-2.

14. Liu Y, Tabarroki A, Billings S, et al. Successful use of very low dose subcutaneous decitabine to treat high-risk myelofibrosis with Sweet syndrome that was refractory to 5-azacitidine. Leuk Lymphoma 2014;55:447-9.

15. Lin CH, Yeh SP, Lin TY. Azacitidine is effective for the treatment of myelodysplastic syndrome and accompanied Sweet syndrome. Ann Hematol 2015;94:1925-6.

(English Language Editors: R. Scott) 